of steroids and azathioprine. However, steroids are not associated with indeterminate elispot results [4], and a positive elispot result has been demonstrated in a patient with chronic azathioprine treatment [5]. We suggest each clinic must establish its own test performance before the T-SPOT ${ }^{\mathrm{TM}}$.TB can be used to rule out active TB disease. Even then, we are reluctant to fully rely on negative T-SPOT ${ }^{\mathrm{TM}}$.TB test results. Withholding therapy while awaiting culture results can only be justified if the patient's condition is closely monitored and precautions to avoid further spreading of Mycobacteria are made.

Case A has been under observation for nearly 2 yrs and to date has not shown any signs of TB disease. In the other three cases atypical Mycobacteria (M. genavense, $M$. avium and $M$. malmoense) were cultured and treated.

Exclusion of active TB will not be feasible in countries with a high incidence of latent TB infection because the background $\mathrm{T}_{-}$SPOT $^{\mathrm{TM}}$.TB positive test results will be high and, as a consequence, the specificity to prove active disease will be low.

Infection control measures will always be undertaken the moment a patient is suspected to suffer from active pulmonary TB. In a hospital setting the patient will most likely be isolated from other patients, in an outpatient setting the patient will be told to stay at home and to not visit places with high numbers of people, such as pubs and bars, supermarkets or sport clubs. Furthermore, the stigma of suffering from TB is a real problem even in the 21st century. Emotional distress for the patient and their close contacts is not to be dismissed. In the Netherlands, the Municipal Health Authority will be notified when there is suspicion of active TB. The Authority will not wait for another 6-10 weeks before starting contact tracing. The first circle of contacts (household members and close friends) will be screened as soon as possible to identify a possible source patient or to diagnose other patients with active TB disease.

In conclusion, we underscore the general point made by J-P. Janssens that an interferon- $\gamma$ release assay should not be used lightly to exclude active tuberculosis. However, in a setting with: 1) low endemicity; 2) the possibility to follow the patient; 3) a proven track record of the facilitating laboratory; and 4) including the T-cell stimulation control test to detect nonresponsive (indeterminate) patients, such an approach is feasible.

\section{R.M. van Leeuwen*, A.W.J. Bossink ${ }^{\#}$ and S.F.T. Thijsen}

Depts of *Internal Medicine, "Pulmonology and Tuberculosis, and "Medical Microbiology and Immunology, Diakonessenhuis Utrecht, Utrecht, The Netherlands.

\section{STATEMENT OF INTEREST}

None declared.

\section{REFERENCES}

1 van Leeuwen RM, Bossink AW, Thijsen SF. Exclusion of active Mycobacterium tuberculosis complex infection with the T-SPOT.TB assay. Eur Respir J 2007; 29: 605-607.

2 Dijkstra F, van Gageldonk-Lafeber AB, Brandsema $\mathrm{P}$, et al. Respiratoire infectieziekten in het jaar 2005/2006. [Respiratory infections in the year 2005/2006.] Infectieziekten Bulletin 2006; 11: 390-397.

3 Hays WL. Statistics. 5th Edn. Oxford, Harcourt Brace College Publishers, 1994.

4 Ferrara G, Losi M, D'Amico R, et al. Use in routine clinical practice of two commercial blood tests for diagnosis of infection with Mycobacterium tuberculosis: a prospective study. Lancet 2006; 367: 1328-1334.

5 Richeldi L, Ewer K, Losi M, et al. Early diagnosis of subclinical multidrug-resistant tuberculosis. Ann Intern Med 2004; 140: 709-713.

\title{
The effect of gas standardisation on exhaled breath condensate $\mathrm{pH}$ and $\mathrm{PCO}_{2}$
}

\section{To the Editors:}

We read with interest the recent article by KULLMANN et al. [1] reporting the effect of gas standardisation on exhaled breath condensate $(\mathrm{EBC}) \mathrm{pH} . \mathrm{pH}$ can be determined immediately upon sampling, without gas standardisation [2], or following EBC gas standardisation in case of delayed analysis [3-5]. The influence of ambient air and analytical sample preparation pose a major problem for $\mathrm{pH}$ and carbon dioxide tension $\left(\mathrm{PCO}_{2}\right)$ determination in EBC. In gas standardisation (argon bubbling or $\mathrm{CO}_{2}$-free gas), $\mathrm{CO}_{2}$ is removed from the sample, thus reducing the effect of $\mathrm{CO}_{2}$ on $\mathrm{pH}$ determination. KullmanN et al. [1] even proposed $\mathrm{CO}_{2}$ standardisation at a
$\mathrm{PCO}_{2}$ of $5.33 \mathrm{kPa}$, physiological alveolar $\mathrm{PCO}_{2}$. Based on the experience with gas determination in blood, which should not be exposed to ambient air, the aim of our study was to determine $\mathrm{PCO}_{2}$ and $\mathrm{pH}$ in argon-overlined EBC immediately upon sampling. To our knowledge, it was the first analysis of argon-overlined EBC.

EBC was collected from a total of 53 children (18 children with gastro-oesophageal reflux (GER), 22 asthmatics and 13 healthy controls), aged 5-16 yrs. All asthmatics received their regular anti-asthmatic treatment with inhaled corticosteroids (ICS) or ICS plus long-acting $\beta_{2}$-agonists for 4 weeks. Chronic cough due to GER was diagnosed by $24-h$ oesophageal $\mathrm{pH}$ monitoring. The 

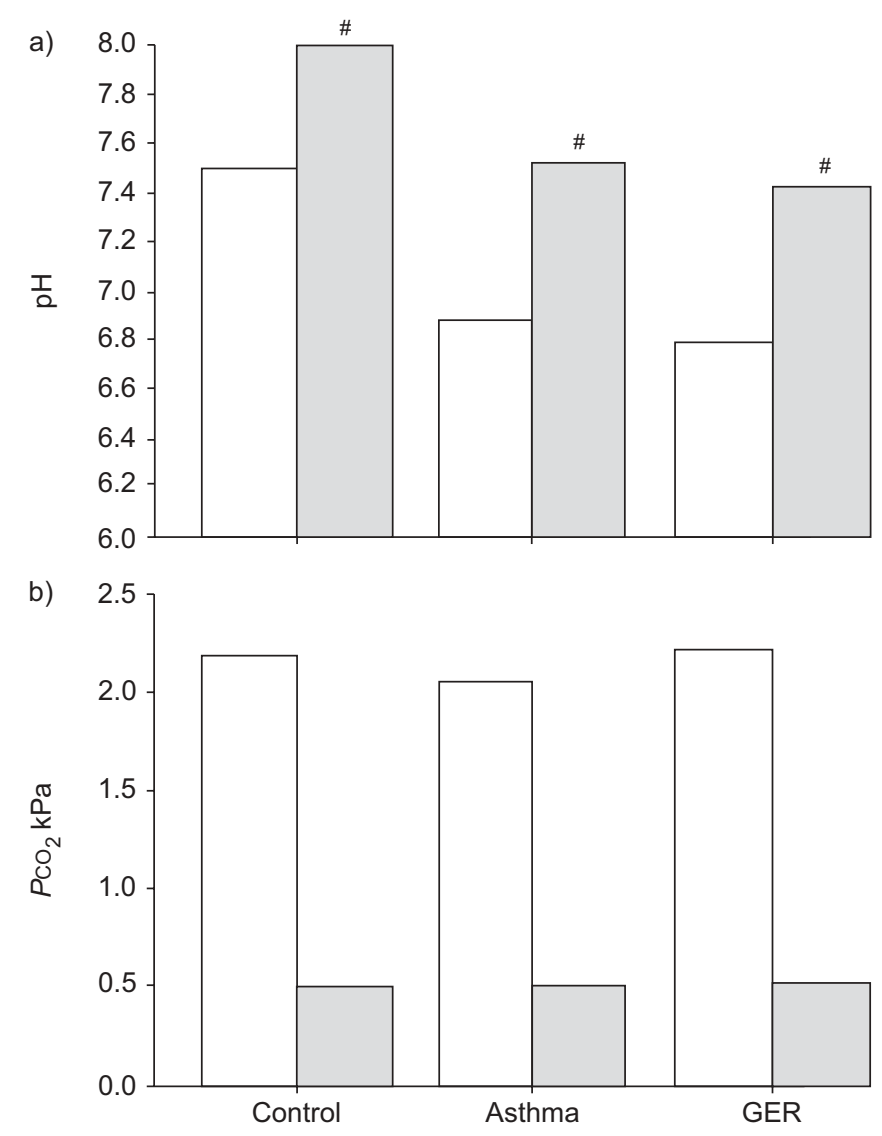

FIGURE 1. Mean a) $\mathrm{pH}$ and b) carbon dioxide tension $\left(\mathrm{PCO}_{2}\right)$ values in controls, asthmatics and patients with gastro-oespophageal reflux (GER). $\square$ : sample A, argon overlining; : sample $B$, argon bubbling. ${ }^{*}: p=0.0000$.

study protocol was approved by the hospital ethics committee (Srebrnjak Children's Hospital, Zagreb, Croatia) and written informed consent was obtained from the parents. Daily between 10:00-12:00 h, two EBC samples were obtained from each subject. EBC was collected using an EcoScreen condenser (Erich Jaeger $\mathrm{GmbH}$, Hoechberg, Germany). The subjects were instructed to breathe tidally for $15 \mathrm{~min}$, wearing a nose clip. The obtained condensate (1.5-2.2 mL) was then deaerated with argon in two ways: 1) sample A obtained on day 1 was argon overlined (6 L. $\mathrm{min}^{-1}$ for $\left.2 \mathrm{~min}\right)$; and 2) sample B obtained on day 2 was submitted to argon bubbling $\left(350 \mathrm{~mL} \cdot \mathrm{min}^{-1}\right.$ for $10 \mathrm{~min}) . \mathrm{pH}$ and $\mathrm{PCO}_{2}$ were determined using an Ecosys II analyzer (Eschweiler GmbH \& Co. KG, Kiel, Germany) with 35 min of EBC A and B sample collection.

The values of $\mathrm{pH}$ and $\mathrm{PCO}_{2}$ showed statistically significant differences according to the method of sample argonisation (fig. 1). The $\mathrm{pH}$ values were significantly lower, and the $\mathrm{PCO}_{2}$ values were significantly higher in samples $A$ than in samples $B$. The mean increase in $\mathrm{pH}$ of sample B was $0.509(7.485 \pm 0.429$ to $7.994 \pm 0.264), 0.642(6.873 \pm 0.312$ to $7.515 \pm 0.222)$ and 0.630 $(6.788 \pm 0.397$ to $7.418 \pm 0.253)$ in controls, asthmatics and GER patients, respectively $(\mathrm{p}=0.0000)$. The mean decrease in $\mathrm{PCO}_{2}$ in sample B was significant in controls, asthmatics and GER patients $(2.22 \pm 0.97$ to $0.52 \pm 0.12,2.08 \pm 1.13$ to $0.53 \pm 0.11$, and $2.25 \pm 1.17$ to $0.53 \pm 0.12$, respectively; $\mathrm{p}=0.0000$ ). Comparison of
$\mathrm{pH}$ and $\mathrm{PCO}_{2}$ measured in children with asthma and GER (in both samples A and B) with those in controls showed no significant difference (considered to be $\mathrm{p}>0.05$ ).

The stability of the analytes influenced by the atmosphere is ensured by the procedure of argon over-lining [2]. Using gas standardisation, $\mathrm{CO}_{2}$ was removed from the sample. These results suggest the $\mathrm{PCO}_{2}$ values in gas-standardised $\mathrm{EBC}$ to be clinically useless; therefore, EBC samples should be submitted to argon overlining for $\mathrm{PCO}_{2}$ determination. $\mathrm{PCO}_{2}$ should be determined as soon as possible (i.e. within $5 \mathrm{~min}$ of condensate preparation). During that period, argon overlining delays $\mathrm{CO}_{2}$ release and $\mathrm{pH}$ increase. In our study, the mean $\mathrm{pH}$ of sample A was in the neutral range in healthy children and in the acid range in children with asthma and GER, which is consistent with current literature [6-8], while the $\mathrm{pH}$ of the gasstandardised sample was within the alkaline range, again in agreement with other literature [3-5].

Despite some limitations of the study, such as the lack of EBC sampling on two consecutive days instead of sample analysis before and after gas standardisation, the results obtained could serve as a basis with which to solve some pre-analytical issues.

In conclusion, when $\mathrm{pH}$ and carbon dioxide tension can be determined immediately upon sampling, we consider that exhaled breath condensate sample argon over-lining should be performed.

\section{S. Dodig*, I. Čepelak", D. Plavec*, Ž. Vlašić*, B. Nogalo* and M. Turkalj*}

*Srebrnjak Children's Hospital, Reference Center for Clinical Paediatric Allergology of the Ministry of Health and Social Welfare, and "Dept of Medical Biochemistry and Hematology, Faculty of Pharmacy and Biochemistry, University of Zagreb, Zagreb, Croatia.

\section{STATEMENT OF INTEREST}

None declared.

\section{REFERENCES}

1 Kullmann T, Barta I, Lazar Z, et al. Exhaled breath condensate $\mathrm{pH}$ standardised for $\mathrm{CO}_{2}$ partial pressure. Eur Respir J 2007; 29: 496-501.

2 Ojoo JC, Mulernnan SA, Kastelik JA, Morice AH, Redington AE. Exhaled breath condensate $\mathrm{pH}$ and exhaled nitric oxide in allergic asthma and cystic fibrosis. Thorax 2005; 60: 22-26.

3 Vaughan J, Ngamtrakulpanit L, Pajewski TN, et al. Exhaled breath condensate $\mathrm{pH}$ is a robust and reproducible assay of airway acidity. Eur Respir J 2003; 22: 889-894.

4 Nicolaou N, Lowe LA, Murray CS, Woodcock A, Simpson A, Custovic A. Exhaled breath condensate $\mathrm{pH}$ and childhood asthma: unselected birth cohort study. Am J Respir Crit Care Med 2006; 174: 254-259.

5 Niimi A, Nguyen LT, Usmani O, Mann B, Chung KF. Reduced $\mathrm{pH}$ and chloride levels in exhaled breath condensate of patients with chronic cough. Thorax 2004; 59: 608-612.

6 Borrill ZL, Smith JA, Naylor J, Woodcock AA, Singh D. The effect of gas standardisation on exhaled breath condensate pH. Eur Respir J 2006; 28: 251-252. 
7 Hunt JF, Fang K, Malik R, et al. Endogenous airway acidification: implications for asthma pathophysiology. Am J Respir Crit Care Med 2000; 16: 694-699.

8 Carraro S, Folesani G, Corradi M, Zanconato S, Gaston B, Baraldi E. Acid-base equilibrium in exhaled breath condensate of allergic asthmatic children. Allergy 2005; 60: 476-481.

DOI: $10.1183 / 09031936.00032507$

\section{From the authors:}

In the last few years, exhaled breath condensate (EBC) sampling has generated rapidly increasing interest, facilitated by the continuous international discussion of different methodological issues surrounding this sampling method under the framework of the European Respiratory Society/American Thoracic Society Task Force [1]. The measurement of different biomarkers has the potential to detect previously unseen processes of the airways, including airway acidification and its change with other disease markers [2,3], the dynamics of mediator changes during exercise-induced bronchospasm [4] and others, but poses several methodological questions for even the most robust and easy-to-perform test in EBC, such as $\mathrm{pH}$ measurement. Our proposal for methodological standardisation of EBC $\mathrm{pH}$ measurement was rather simple: provide the EBC $\mathrm{pH}$ value at a fixed partial EBC carbon dioxide tension $\left(\mathrm{PCO}_{2}\right)$, in order to exclude the uncertainty deriving from differing $\mathrm{CO}_{2}$ content. In our hands, this mode of standardisation was faster, cheaper and six times more precise than the determination of $\mathrm{pH}$ in argon-deaerated samples, although it required multiple measurements and the use of a blood-gas analyser instead of a $\mathrm{pH}$ meter [5].

We were eager to see, therefore, some comments on our approach. The letter of S. Dodig and co-workers, instead of commenting on our approach, shows an "original $\mathrm{CO}_{2}$ saving" attempt by overlining EBC samples with argon. The problem with this approach is still the fact that during EBC sampling the $\mathrm{PCO}_{2}$ content may change, so the saving attempt may only slow this process down. There are no data provided by $\mathrm{S}$. Dodig and co-workers on the $\mathrm{pH}$ of raw EBC samples, so it is hard to evaluate the effect of argon overlining. Looking at the data provided (only the mean can be estimated from figure 1 in the letter of S. Dodig and co-workers), $\mathrm{pH}$ and $\mathrm{PCO}_{2}$ values seem to be in the range of those in raw EBC samples [5, 6], so it is hard to appreciate that the method actually saved some $\mathrm{CO}_{2}$ in the samples. At the same time, S. Dodig and co-workers demonstrated a lower degree of change by argon-deaeration (instead of $\sim 1 \log$ order of change described by most groups, they found $\sim 0.5 \log$ order increase), which is probably the result of a higher end $\mathrm{PCO}_{2}$ level in their samples after deaeration, compared with the results of others. Therefore, according to the observable data, we are even more convinced that to read EBC pH at fixed $\mathrm{PCO}_{2}$ is a worthy approach that excludes the potential confounding effect of $\mathrm{CO}_{2}$. Of course, the reading of $\mathrm{pH}$ in native samples immediately after collection or after argon deaeration (even without $\mathrm{PCO}_{2}$ measurement) may provide useful information, but when small changes are expected an improvement in reproducibility enhances our potential to determine those changes.

Therefore, work on any area of developing newer, more reproducible methods for exhaled breath condensate biomarkers are most welcome in the field, because they can help us to establish the real usefulness of this sampling technique.

\section{Horvath}

Institute of Human Physiology and Clinical Experimental Research, Semmelweis University, Budapest, Hungary.

\section{STATEMENT OF INTEREST}

None declared.

\section{REFERENCES}

1 Horvath I, Hunt J, Barnes PJ, et al. Exhaled breath condensate: methodological recommendations and unresolved questions. Eur Respir J 2005; 26: 523-548.

2 Hunt JF, Fang K, Malik R, et al. Endogenous airway acidification. Implications for asthma pathophysiology. Am J Respir Crit Care Med 2000; 161: 694-699.

3 Noble DD, McCafferty JB, Greening AP, Innes JA. Respiratory heat and moisture loss is associated with eosinophilic inflammation in asthma. Eur Respir J 2007; 29: 676-681.

4 Csoma Z, Huszar E, Vizi E, et al. Adenosine level in exhaled breath increases during exercise-induced bronchoconstriction. Eur Respir J 2005; 25: 873-878.

5 Kullman T, Barta I, Lazar Z, et al. Exhaled breath condensate pH standardised for $\mathrm{CO}_{2}$ partial pressure. Eur Respir J 2007; 29: 496-501.

6 Horvath I, Szili B, Kullmann T. The effect of gas standardisation on exhaled breath condensate pH. Eur Respir J 2006; 28: 252-253. 